DESENVOLVIMENTO
EMEIO AMBIENTE

\title{
As diferentes narrativas alimentares do agronegócio
}

\section{The different food narratives of agribusiness}

\author{
Caio POMPEIA ${ }^{1 *}$, Sergio SCHNEIDER ${ }^{2}$ \\ ${ }^{1}$ Universidade de São Paulo (USP), São Paulo, SP, Brasil. \\ ${ }^{2}$ Universidade Federal do Rio Grande do Sul (UFRGS), Porto Alegre, RS, Brasil. \\ *E-mail de contato: caporine@gmail.com
}

Artigo recebido em 8 de outubro de 2020, versão final aceita em 6 de abril de 2021, publicado em 30 de junho de 2021 .

RESUMO: $\quad$ Frente à ampliação global de problemas de saúde pública relacionados à alimentação, a literatura tem dispensado maior atenção ao estudo das múltiplas determinações que podem influenciar a transição a sistemas agroalimentares sustentáveis e saudáveis. Procurando contribuir com o debate, este artigo analisa as narrativas de diferentes agentes relacionados ao campo do agronegócio sobre duas agendas: a da segurança alimentar e nutricional (SAN) e a da alimentação adequada e saudável. O objetivo é examinar os modos como tais narrativas têm sido mobilizadas e modificadas, tanto para responder a críticas, quanto para legitimar posicionamentos sobre políticas públicas e propostas legislativas. O período abordado corresponde ao intervalo entre os anos 1990 e a década de 2020, e os materiais empíricos utilizados incluem documentos corporativos e estatais, manifestações públicas de agentes privados e políticos, e relatórios de organizações internacionais. Tais materiais são abordados com foco no agenciamento de categorias, nas variações discursivas provocadas pelas críticas e na heterogeneidade de representações do campo. Os resultados mostram que, ao perderem legitimidade quanto à agenda da SAN no país, representações dominantes das cadeias de commodities passam a privilegiar discursos sobre suas contribuições nas exportações desses produtos, ao passo que uma nova controvérsia ganha impulso, aquela que relaciona a alimentação à saúde.

Palavras-chave: agronegócio; narrativas; segurança alimentar e nutricional; alimentação adequada e saudável.

ABSTRACT: In the face of the global expansion of environmental problems and public health issues related to food, the literature has given greater attention to the study of the multiple determinations that may influence the transition to sustainable and healthy agri-food systems. Seeking to contribute to the debate, this article analyzes the narratives of different actors related to the agribusiness field on two agendas: food and nutrition security and adequate nutrition. The objective is to examine the ways in which these narratives have been 
mobilized and modified, both to respond to the critiques and to legitimize claims concerning public policies and legislative proposals. Covering the period between the 1990s and the 2020s, the empirical materials include corporate and state documents, public manifestations by private and political actors, and reports by international organizations. They are approached with a focus on the mobilization of categories, the discursive variations provoked by criticisms, and the heterogeneous representations of the field. The results show that, by losing legitimacy regarding the food and nutrition security agenda in Brazil, dominant representations of the commodity chains begin to privilege discourses that stress their contributions to the exports of these products, while a new controversy gains momentum, one that relates food to health.

Keywords: agribusiness; narratives; food and nutrition security; adequate nutrition.

\section{Introdução}

O presente artigo analisa as narrativas alimentares de diferentes agentes dominantes no campo do agronegócio, especificamente aquelas relacionadas às agendas da segurança alimentar e nutricional (SAN) e da alimentação adequada e saudável. Examinam-se os modos como essas narrativas são agenciadas para fins políticos e de que formas elas se modificam em contextos de controvérsias alimentares.

Se a literatura científica tem identificado consideráveis avanços nas políticas públicas ligadas a ambas as agendas no Brasil, simultaneamente tem evidenciado os desencontros e dificuldades que se impõem às mesmas (Belik, 2003; 2012; Castro, 2015; Graziano da Silva, 2003; Jaime et al., 2018; Maluf et al.; 2001; Maluf et al., 1996; Marques, 2013; 2015).

Quanto aos bloqueios e reveses que têm ocorrido em relação às políticas alimentares - a exemplo daqueles recentes relativos ao Conselho Nacional de Segurança Alimentar e Nutricional (Consea) e ao Guia Alimentar para a População Brasileira (Asbran, 2020; Castro, 2019; Jaime, 2019; Recine et al., 2020; Pompeia: no prelo) -, a compreensão dos distintos interesses, discursos e posições dos atores que as disputam são notavelmente relevantes.
Dentre os agentes com poder de influência significativa nesses conflitos estão líderes proeminentes, corporações e organizações empresariais dominantes ligados às cadeias agroalimentares. Nos estudos sobre eles, é possível destacar as abordagens das posições da então Associação Brasileira de Agribusiness (Abag) (Maluf et al., 1996; Marques, 2015) sobre os debates ligados à SAN nos anos 1990, e as investigações da ação corporativa política de indústrias de alimentos e bebidas ultraprocessados no Brasil (Castro, 2015; Louzada et al., 2019; Mialon \& Gomes, 2019; Mialon et al., 2018).

Este trabalho tem o objetivo de contribuir com a literatura por meio de uma análise detida sobre três ordens de narrativas alimentares de agentes do campo do agronegócio: (1) as ligadas à SAN no Brasil; (2) as relacionadas à ideia de o país operar como "celeiro do mundo"; e, por fim, (3) aquelas que vinculam a alimentação à saúde pública.

Para cumprir esse objetivo, atenta-se, de uma parte, para a mobilização de expressões como a própria noção de segurança alimentar e a ideia-força "alimentação e saúde". Não casualmente, especialistas têm salientado a polissemia e os embates relacionados a tais expressões (Belik, 2003; Maluf et al., 2001; Marques, 2015; Paiva et al., 2019). Nesse sentido, baseamo-nos no enfoque da Antropologia do Político (Montero, 2012; Montero et al., 
2012), particularmente em seu modelo de análise do agenciamento de categorias, central para examinar a construção de narrativas e a atuação de coletivos políticos diante de controvérsias. Com fundamento em Montero (2012), as controvérsias são entendidas aqui como situações de debates que gradualmente implicam a constituição de um problema social, a ser tratado na esfera pública.

De outra parte, inspiramo-nos em Boltanski \& Chiapello (2005) ao atentarmos às variações das narrativas corporativas que ocorrem diante de críticas alimentares e das influências político-econômicas dessas contestações. É importante ressaltar que neste texto focalizamos prioritariamente as mudanças observáveis em discursos e programas corporativos, o que implica colocar o exame das críticas em segundo plano.

Os materiais utilizados na análise abrangem cartas programáticas das associações ligadas às cadeias agroalimentares, posicionamentos de líderes empresariais, manifestações públicas de políticos, documentos e informações estatais e relatórios de organizações internacionais. Tendo em consideração o escopo do artigo, foram selecionados os materiais mais relevantes com fundamento no livro Formação Política do Agronegócio (Pompeia, 2021), que trata da constituição e da consolidação do heterogêneo e dinâmico campo do agronegócio no Brasil.

Mas antes de analisarmos cada uma das três ordens de narrativas, apresentamos uma contextualização do agronegócio no país em relação às questões alimentares globais.

\section{O agronegócio no Brasil e as questões alimentares globais}

Não restam dúvidas sobre a relevância atual das exportações de commodities agropecuárias para a balança comercial brasileira (Mapa, 2016; 2021) - embora devam ser considerados, para esse resultado, dentre outros fatores, (1) a não cobrança do Imposto sobre Circulação de Mercadorias e Serviços (ICMS) em relação às vendas externas de produtos primários e (2) o fato de o Ministério da Agricultura, Pecuária e Abastecimento (Mapa) não incluir, no cálculo das exportações líquidas do agronegócio, os saldos comerciais negativos a montante das cadeias produtivas, que ocorrem em razão das consideráveis importações de fertilizantes e agrotóxicos (ver Carneiro da Cunha et al., 2017, p. 420-421).

Também não é novidade que a economia nacional apresente uma dependência histórica e estrutural em relação à utilização de seus recursos primários, terra e minérios, sob a qual se soergueram formas de produção de riqueza que se desdobraram em ciclos econômicos (Caio Prado Júnior) e forjaram uma economia agroexportadora periférica e dependente (Celso Furtado) no cenário global. Embora seja doloroso admitir, o Brasil continua sendo um país de inserção internacional subordinada. Em seu magistral livro sobre a formação do capitalismo tardio brasileiro, Cardoso de Mello \& Novais (2008, p. 644) assinalam "a que ponto chegamos", realçando o fracasso da modernização econômica e social, que não foi capaz de gerar uma sociedade menos desigual e injusta. Outro grande observador da "longue durée" brasileira, Luiz Carlos Bresser-Pereira, destaca em seu "A construção política do 
Brasil" que a participação da indústria no Produto Interno Bruto (PIB) do Brasil vinha em tendência crescente de 1950 a 1986, regredindo desde então de "maneira brutal" (2014, p. 19). O autor descreve o país em sua configuração atual como uma sociedade nacional-dependente a procura de uma estratégia de desenvolvimento.

É possível que o grupo político e intelectual que está no poder no Brasil, e exerce uma hegemonia econômica baseada em visão ultraliberal de subordinação à ordem global, tenha entendimento contrário aos autores destacados. Para os atuais governantes, a desindustrialização acelerada e precoce da economia brasileira pode ser compensada com a inserção na economia mundial por intermédio da exportação de commodities, como soja, carnes, produtos florestais, álcool-açúcar e café, além de minério de ferro e alguns outros itens. Sob essa ótica, o agronegócio brasileiro é considerado um segmento altamente moderno, competitivo e robusto da economia nacional, não havendo motivos pertinentes para ser criticado ou desincentivado (Neves, 2016).

Mas em geral o que aparenta ser uma fortaleza também esconde grandes fragilidades. Já não há dúvidas de que o século XXI deverá fomentar a transição para uma nova matriz energética e uma economia de baixo carbono que contribuam na mitigação das mudanças climáticas, assim como precisará criar as condições para alimentar, de forma adequada e saudável, uma população cada vez maior e mais urbanizada. Contudo, há severas barreiras que se erguem nesse contexto.

Por um lado, esses reptos não poderão ser alcançados por meio da base tecnológica que nos trouxe até aqui, o que torna premente a inovação sob perspectiva marcadamente diferente da que tem predominado. São muitos os diagnósticos de instituições reconhecidas de que os sistemas agroalimentares têm implicado a degradação dos solos e das águas, influenciado a perda de biodiversidade e contribuído de modo decisivo para as mudanças climáticas - minando perigosamente nosso futuro bem-estar (Global Panel, 2020; IPCC, 2019). Tampouco são escassas as publicações em revistas científicas prestigiosas com conclusões similares. Segundo Tilman \& Clark (2014), as atividades agrícolas no mundo emitem mais de um quarto dos gases de efeito estufa (GEE), além de poluírem as águas fluviais e marítimas com diversos agroquímicos. Para Poore \& Nemecek (2018), a produção de alimentos responde por aproximadamente $32 \%$ da acidificação terrestre global e $78 \%$ da eutrofização, e suas emissões podem alterar fortemente a composição de espécies dos ecossistemas naturais, reduzindo a biodiversidade e a resiliência ecológica.

Por outro lado, o agronegócio e o sistema agroalimentar globalizado têm sido identificados de forma cada vez mais recorrente como responsáveis, em importante medida, pela epidemia de obesidade e outras doenças crônicas não transmissíveis (DCNT) relacionadas à alimentação. Estudos da área de saúde pública, medicina, nutrição e epidemiologia estão apontando relações causais entre a alimentação inadequada e tais doenças (Popkin \& Reardon, 2018; Tilman \& Clark, 2014; Willet et al. 2019). Outro exemplo sintomático a esse respeito é o relatório do Banco Mundial (2017), que destaca o fato de a obesidade ter se tornado um problema mundial que afeta todos os países e tem um custo estimado de US\$ 2 trilhões por ano, sendo que $68 \%$ das mortes são causadas por DNCT. Ao mesmo tempo, surgem evidências de que a obesidade é fator de risco severo para pessoas que contraiam 
o novo coronavírus (SARS-CoV-2) (Public Health England, 2020).

Ademais, o relatório Global Panel on Agriculture and Food Systems for Nutrition (2020) alerta que existem 690 milhões de pessoas cronicamente subnutridas em todo o mundo, ao passo que quase 3 bilhões não conseguem pagar por alimentação saudável e dietas de baixa qualidade estão associadas a 11 milhões de mortes por ano. Apesar do aumento do interesse pela nutrição nos últimos anos, o progresso para reduzir a insegurança alimentar (INSAN) e atingir o Objetivo de Desenvolvimento Sustentável 2 da Organização das Nações Unidas (ONU) ainda é muito lento. A subnutrição permanece preocupantemente alta nas regiões mais pobres do mundo, e o sobrepeso e a obesidade estão aumentando em quase todos os países. Todas as indicações são de que os impactos mais amplos da atual pandemia de coronavírus estão exacerbando a desnutrição. Pessoas que enfrentam essa condição em suas variadas formas também têm maior probabilidade de serem gravemente afetadas pela Covid-19.

No Brasil, os efeitos do sistema industrial de produção agrícola e alimentar sobre a saúde humana são igualmente perceptíveis. De acordo com a Pesquisa de Vigilância de Fatores de Risco e Proteção para Doenças Crônicas por Inquérito Telefônico (Vigitel), do Ministério da Saúde, 19,8\% da população adulta no país apresentava obesidade em 2018 (MS, 2019). Trata-se de um crescimento acentuado em relação a 2006, quando a estimativa do mesmo público nessa situação correspondeu a 11,8\% (MS, 2019). Em 2016, a obesidade, a dia- betes e outras DCNT relacionadas à alimentação inadequada foram responsáveis por $74 \%$ das mortes totais no Brasil (WHO, 2018).

Paralelamente, a publicação recente da Pesquisa de Orçamentos Familiares (POF) 2017-2018 pelo IBGE (2020a) mostrou um claro aumento na prevalência de insegurança alimentar grave no país. A POF 2017-2018 identificou - com base na aplicação, entre junho de 2017 e julho de 2018, da Escala Brasileira de Insegurança Alimentar (Ebia) ${ }^{1}$ - que a tendência de queda na ocorrência de INSAN grave em domicílios particulares no país foi revertida. Se os dados de 2004, 2009 e 2013 da Pesquisa Nacional por Amostra de Domicílios (PNAD) - também com a utilização da Ebia - apontavam, respectivamente, a prevalência da INSAN grave em $6,9 \%, 5,0 \%$ e $3,2 \%$, no biênio 2017-2018 ela voltou a subir, chegando a $4,6 \%$.

Realizada essa breve contextualização, passamos, em seguida, à análise das três narrativas alimentares.

\section{Disputas sobre a agenda de segurança alimentar e nutricional no Brasil}

O primeiro momento em que núcleos com representação intersetorial ligados ao agronegócio dispensaram atenção sistemática às questões alimentares ocorreu no início dos anos 1990, justamente quando o tema passava a adquirir maior importância na esfera pública internacional. O interesse pelo assunto seria ampliado durante o começo dessa década, até receber maior materialidade com

\footnotetext{
${ }^{1}$ Por meio de perguntas diretas sobre a situação alimentar dos últimos três meses nos domicílios, a Ebia permite classificá-los em quatro diferentes graus: segurança alimentar, insegurança alimentar leve, moderada e grave (IBGE, 2020a).
} 
a Conferência Internacional sobre Nutrição, realizada conjuntamente pela Organização das Nações Unidas para Agricultura e Alimentação (FAO) e pela Organização Mundial da Saúde no final de 1992 (Pompeia, 2021).

A declaração final da conferência exclamava que o acesso ao alimento seria um direito individual, e enfatizava a orientação para a eliminação da fome e a redução de todas as formas de desnutrição nos países. Segundo o documento, caberia aos governos nacionais atuarem para garantir esse direito, por meio da priorização orçamentária, do planejamento e da implementação de políticas públicas (United Nations, 1992).

Simultaneamente, a agenda contra a fome vinha obtendo maior proeminência na opinião pública brasileira, o que contribuiu para abrir espaço a uma proposta de política de segurança alimentar do Partido dos Trabalhadores (PT) que anteriormente recebera menor atenção (Maluf et al., 1996; Marques, 2015). Ao notar uma maior abertura para o assunto, o PT anunciou, pouco antes da passagem de 1992 para o ano seguinte, que iria entregá-la ao então presidente Itamar Franco.

A proposta - que previa a distribuição gratuita de alimentos para populações em insegurança alimentar, a utilização de vales-refeição e o apoio a pequenos agricultores - dialogava com as recomendações direcionadas aos Estados nacionais no âmbito da ONU. Itamar Franco assentiu à proposição, incorporando-a parcialmente em seu plano de governo. Em paralelo, a sociedade civil ampliava, sob liderança de Herbert de Souza (Betinho), as mobilizações sobre o tema. Em abril de 1993, ele e outros atores lançaram uma campanha para dar impulso a tal movimento, a chamada "Ação da Cidadania Contra a Fome, a Miséria e Pela Vida"2. Tal ordem de fatores, catalisada por críticas da referida proposta do PT a parte dos agentes empresarias ligados às cadeias agroalimentares (ver Belik, 2012; Maluf et al., 1996), forçaria mudanças discursivas e programáticas entre atores corporativos, o que ocorreu sobretudo por meio do agenciamento da expressão "segurança alimentar".

Entretanto, tais alterações não seriam imediatas: a princípio, as reações de entidades lideradas pela agricultura patronal e por indústrias foram pouco sensíveis à complexidade do problema. De fato, manifestações tanto da Associação Brasileira das Indústrias da Alimentação (Abia, atualmente Associação Brasileira da Indústria de Alimentos) quanto da Sociedade Nacional de Agricultura (SNA) utilizaram a ideia de segurança alimentar para tratar das aptidões de exportação do país, como se a preocupação com essa problemática dissesse respeito, sobretudo, a potenciais importadores, a exemplo de países da Europa, e não ao Brasil, onde havia número absoluto muito superior de pessoas com fome e desnutrição ${ }^{3}$ (ver Klotz, 1992; Alvarenga, 1992).

Mais atenta aos rumos dos debates na esfera pública, a Associação Brasileira de Agribusiness (posteriormente Associação Brasileira do Agronegócio) agiu de forma diferente, defendendo as corporações como fundamentais para a promoção da segurança alimentar no país (Maluf et al., 1996; Marques, 2015). Na cerimônia de posse da diretoria

\footnotetext{
${ }^{2}$ Para mais informações, consultar o site da Ação da Cidadania, disponível em: $<$ http://www.acaodacidadania.com.br/?page=home $>$. Acesso em: ago. 2020.
}

${ }^{3}$ Para uma avaliação crítica das noções de fome e desnutrição, ver Monteiro (2003). 
da associação, seu presidente, Ney Bittencourt de Araújo, argumentou que “[...] o desenvolvimento sustentado do Brasil começa, necessariamente, pela segurança alimentar" (Bittencourt de Araújo, 2013, p. 12). No livro que acompanhou o lançamento da organização, o assunto receberia relevante destaque. O título da obra era, a propósito, Segurança alimentar-uma abordagem de agribusiness (Abag, 1993). Defendia-se, então, ser esse desafio sua principal "responsabilidade social":

A história dos países desenvolvidos revela que foi a adoção de uma política de segurança alimentar que lhes assegurou crescimento econômico com demanda sustentada, dando-lhes estabilidade e melhor distribuição dos frutos do progresso material e melhor qualidade de vida. Não se diga que eles o fizeram porque são ricos. A verdade é o contrário. Eles tornaram-se ricos porque assim o fizeram (Abag, 1993, p. 10).

Fundamentados nessa argumentação, os autores do livro pleiteavam, concomitantemente, aumento de subsídios e diminuição de tributos às cadeias de commodities. $\mathrm{O}$ atendimento dessa dupla reivindicação daria sustentação à ampliação da produção, com base no seguinte pressuposto: "Não se implementa uma política de segurança alimentar sem alimentos" (Abag, 1993, p. 21). Essas argumentações guardavam coerência com o posicionamento público de Roberto Rodrigues, que, por sinal, estava articulado com a engenharia institucional que resultara na Abag (Pompeia, 2021). Rodrigues afirmava então que a ampliação da oferta de alimentos no país - a ser, segundo ele, promovida com medidas como a diminuição de tributos - era passo fundamental para diminuir a prevalência de desnutrição (Rodrigues, 1993).
Embora o texto da Abag enfatizasse, indubitavelmente, a oferta de alimentos como dimensão central no combate à insegurança alimentar, ele não pudera se abster de tratar do tema do acesso, que então adquirira relevo particular na opinião pública. A propósito, a desestabilização de argumentos que diminuíam a relevância do acesso, como aqueles defendidos por corporações no âmbito de eventos da FAO (Pompeia, 2021), começara a ter maior eficácia com as extraordinárias análises de Amartya Sen.

Com efeito, o economista indiano havia contestado a centralidade da oferta em debates sobre insegurança alimentar ao identificar, de forma bem fundamentada, que as falhas das variadas formas de obtenção de alimentos - como compra, produção própria das famílias ou políticas governamentais - podiam operar para a ocorrência da fome mesmo em regiões em que a disponibilidade não fosse problemática (Sen, 1981). Sintonizada com as controvérsias sobre determinações da fome e da desnutrição, e, particularmente, com as críticas aos discursos corporativos predominantes, a Abag apresentava então a seguinte definição de segurança alimentar: "[...] o acesso assegurado a cada família à quantidade necessária de alimentos para garantir uma dieta adequada a todos os seus membros para uma vida saudável" (Abag, 1993, p. 21).

Combinando, portanto, os dois fatores apontados acima - oferta e acesso -, a Abag sugeria a criação de um pacto nacional composto por uma série de políticas macroeconômicas e setoriais. Os principais mecanismos advogados eram tanto uma política de aumento do poder real de compra dos salários, e ações relacionadas à merenda escolar e a vales para compra de comida, quanto a redução de custos de comercialização e distribuição de alimentos (incluindo a diminuição dos impostos sobre 
esses produtos) e a melhoria da infraestrutura para as cadeias produtivas (Abag, 1993).

É necessário ressaltar que, para além das proposições, Bittencourt de Araújo empenhou-se diretamente com as políticas ligadas ao tema, tendo participação ativa (e elogiada por Betinho) no então chamado Conselho Nacional de Segurança Alimentar, criado em 1993 por Itamar Franco (Peliano, 1996; Souza, 1996). De todo modo, era inquestionável que a estratégia de inserir a Abag e outros agentes corporativos como fator indispensável para o enfrentamento da fome e da desnutrição apresentava dois ganhos potenciais. $\mathrm{O}$ primeiro, de legitimidade perante a opinião pública e o governo, sendo necessário considerar que prevalecia, na primeira metade dos anos 1990, o enfraquecimento de instrumentos e ações estatais de apoio às atividades agropecuárias (Delgado, 2012); o segundo, de incentivo à ampliação do mercado interno de alimentos, o que aumentaria a demanda direcionada às cadeias.

Ainda que a prevalência de insegurança alimentar continuasse a ser um grave problema no país após o biênio 1992-1993, seu tratamento na esfera pública perderia intensidade - sendo a extinção do Consea uma das expressões mais visíveis desse processo. Com a diminuição do vigor das críticas a essa questão alimentar - sendo este um fator essencial para a promoção de mudanças em ideologias relacionadas a atividades econômicas (Boltanski \& Chiapello, 2005) -, líderes políticos do campo do agronegócio deixaram de mobilizar a noção de SAN com o mesmo entusiasmo e frequência, como fica demonstrado, por exemplo, pelo diminuto espaço que o tema teria no mais importante documento programático das associações ligadas ao campo do agronegócio da segunda metade dos anos 1990, organizado no âmbito do Fórum Nacional da Agricultura (Mapa, 1998).

Essa orientação somente foi revista de forma relevante no começo da década de 2000, período em que a agenda da SAN voltara a obter proeminência na opinião pública brasileira (Graziano da Silva, 2003). Efetivamente, a ampliação dessa atenção ocorreu a partir do lançamento do Projeto Fome Zero, em outubro de 2001, no processo que levaria Luiz Inácio Lula da Silva a vencer as eleições presidenciais do ano seguinte (Belik, 2012). No dia em que assumiu o cargo, o presidente da República afirmou que o fim da fome seria uma causa nacional. Ele complementou, na ocasião, que "se, ao final do meu mandato, todos os brasileiros tiverem a possibilidade de tomar café da manhã, almoçar e jantar, terei cumprido a missão da minha vida" (MRE, 2008, p. 9).

Ainda durante o ambiente pré-eleitoral, a Abag vinha acompanhando atentamente as posições do PT sobre o tema, uma vez que Lula se apresentava como líder nas pesquisas de intenção de votos. Ao longo da campanha, cabe acrescentar, o candidato tinha feito ponderações críticas ao que entendia como uma contradição entre a pujança nas exportações de commodities agropecuárias e a alta prevalência de insegurança alimentar no Brasil. Por essa e outras razões - como a aproximação do candidato em relação a movimentos sociais de luta pela terra -, havia relevante tensão, por parte de líderes do campo do agronegócio, de que, em sua provável gestão, pudesse ser ameaçada a parceria estratégica entre as principais cadeias de commodities agropecuárias e o Executivo (Delgado, 2012).

Em seu $1^{\circ}$ Congresso Brasileiro de Agribusiness, realizado em meados de 2002, a associação, à época presidida por Roberto Rodrigues, organizou 
um conjunto de sugestões que dialogavam diretamente com as propostas de segurança alimentar advogadas pelo PT (Abag, 2002). Na carta política, retomava-se o apoio - em parte relevante já expresso em 1993 - a programas de alimentação para a população, à ampliação da merenda escolar, às bolsas e doações emergenciais e à educação alimentar. Ao mesmo tempo, defendia-se a importância de a política de SAN ser dotada de orçamento previamente definido, o que poderia atribuir previsibilidade a seu planejamento estratégico. Nada disso seria suficiente, declarava-se no documento, se não houvesse valorização do poder real de compra dos salários. Complementando o que se podia caracterizar, concomitantemente, como estratégia de expansão do mercado interno de alimentos, propunha-se a desoneração da cesta básica e a redução de custos em distribuição e comercialização (Abag, 2002).

No entanto, cabe sublinhar que a ênfase era dispensada, na carta política, à dimensão da oferta - a despeito de o Brasil não ter, então, problemas de maior monta quanto à disponibilidade de alimentos, mas sobretudo quanto ao seu acesso pela população de renda mais baixa (Belik, 2003). Nesse sentido, a Abag solicitava robusto apoio estatal para o crescimento da produção de grãos, carnes, café, cana-de-açúcar e laranja, justificando que os benefícios do estímulo a essas commodities seriam, dentre outros, a melhoria da alimentação dos brasileiros. A entidade (2002, p. 1) afirmava que "o consumidor tem muito mais oportunidades de escolha, de construir uma dieta variada, mais barata e com alimentos de qualidade". Note-se o argumento genérico sobre a qualidade dos alimentos, tema que viria, nos anos 2010, a ser mais bem problematizado na literatura, como mostramos com mais detalhes à frente neste artigo.
É importante reconhecer, a despeito de seu caráter excludente e concentrador, as relevantes consequências que as transformações da base técnica de parte da agropecuária tiveram em termos de aumento de sua produção e produtividade no Brasil, envolvendo, nesse processo, tanto parcelas dos estabelecimentos patronais quanto dos familiares. As influências dessas modificações sobre a ampliação da oferta da carne de frango no país são um de seus principais desdobramentos, dentre vários que houve (Embrapa, 2018). Por outro lado, é indispensável considerar que o aumento da oferta de alimentos no país não pode ser tomado, per se, como equivalente à promoção da $\mathrm{SAN}$ - pois minoraria, ou elidiria, a relevância dos distintos mecanismos que promovem o acesso a eles.

De toda forma, a capacidade da Abag em apresentar narrativas que pretendiam compatibilizar as dimensões da oferta e do acesso a alimentos foi uma das razões que contribuíram para que o presidente eleito Lula convidasse Rodrigues a chefiar o Mapa. No ministério, as práticas seriam diferentes das posições públicas da associação de agribusiness sobre SAN - em contraste, cumpre enfatizar, com o notável empenho de Bittencourt de Araújo na década anterior.

O desencontro entre posicionamentos públicos e ações era considerável porque o grupo que assumiu o Mapa se esforçou, primordialmente, para defender os interesses de agentes patronais relacionados à agropecuária, como ficou evidente, por exemplo, em sua aproximação com a Frente Parlamentar da Agropecuária (FPA) e em seu bloqueio à tentativa de democratização do acesso às pesquisas da Empresa Brasileira de Pesquisa Agropecuária (Embrapa) (ver Pompeia, 2020a). Tratando retoricamente de todos os estabelecimentos rurais, mas privilegiando, na 
prática, os mais bem consolidados agentes patronais e as indústrias, o ministro argumentou que a produção agropecuária seria o fundamento para o êxito do combate à fome. Segundo ele, "o lastro do Programa Fome Zero é a produção rural. Vamos produzir mais comida, e isto demandará mais tecnologia, adubos, máquinas, defensivos, sementes, rações, genética animal, caminhões, armazéns e mais distribuição" (Rodrigues, 2003, p. B5).

Para além dos atores que lideravam o Mapa, houve diferentes reações corporativas às iniciativas do governo contra a fome: a Cargill e políticos norte-americanos articulados com multinacionais pleitearam benefícios fiscais para atuarem com o projeto; a Monsanto aproveitou o momento de maior sensibilidade pública com a questão alimentar para advogar pela rápida liberação de transgênicos no país; e a Associação Brasileira de Supermercados mostrou distanciamento do problema de saúde pública, privilegiando o tratamento da segurança alimentar na chave da inocuidade de alimentos (Governo..., 2003; SNA, 2003). Todas alheias aos desafios assumidos pela estrutura administrativa provisória que daria origem ao Ministério do Desenvolvimento Social e Combate à Fome (MDS), por meio do qual se aprofundaria, juntamente ao Ministério do Desenvolvimento Rural (MDA), uma matriz de políticas agrícolas e sociais de promoção da segurança alimentar e nutricional.

A partir da segunda metade dos anos 2000, tal matriz ganharia maior eficácia (Belik, 2012), contribuindo de maneira significativa, juntamente a políticas macroeconômicas, para a promoção da SAN no Brasil. Entre 2004 e 2009, a prevalência de segurança alimentar subiu de $65,1 \%$ para $69,8 \%$ dos domicílios particulares no país; em 2013, a PNAD apontou essa prevalência em 77,4\% (IBGE, 2020a). Para a contínua qualificação dos instrumentos administrativos voltados a promover a SAN, foi vital, cumpre adicionar, a participação da sociedade civil, principalmente por meio do Consea e das Conferências Nacionais de Segurança Alimentar e Nutricional.

Simultaneamente ao fortalecimento das referidas políticas, cálculos realizados a partir de dados do Censo Agropecuário de 2006 começavam a adquirir projeção na esfera pública nacional. Eles apontavam que a "agricultura familiar" respondia pela oferta de parcelas muito consideráveis de produtos essenciais no mercado interno - com destaque para mandioca, feijão, leite e carne suína (IBGE, 2009, p. 20).

Em consequência, as narrativas de SAN de atores dominantes do campo do agronegócio perdiam, gradualmente, legitimidade. Assim, a capacidade de tais atores para agenciar a noção de segurança alimentar em relação ao Brasil diminuiu sensivelmente. No documento de pleitos aos presidenciáveis de 2010 organizado pela Abag e pela Federação das Indústrias do Estado de São Paulo (Fiesp), o apoio às políticas relacionadas à promoção de SAN não teria espaço. A propósito, a expressão "segurança alimentar" seria usada somente uma vez nas 34 páginas da carta corporativa, dentro de seção sobre "imagem e valorização" do agronegócio (Abag, 2010, p. 20).

Ao mesmo tempo, dado que o país se consolidava como um dos principais exportadores de commodities no mundo, o uso predominante da ideia de SAN por elites do campo foi deslocado para fora do âmbito nacional, conforme se examina na seção seguinte. 


\section{As narrativas de "alimentar o mundo" contra as politicas e normas socioambientais}

A segunda ordem de narrativas analisada no trabalho vincula-se aos usos da noção de SAN em relação à esfera internacional, juntamente a expressões correlatas, a exemplo de "alimentar o mundo". Embora não fossem novidade no país, elas adquiriram maior destaque público na primeira metade dos anos 2010, precisamente quando se ampliava o vigor das críticas "verdes" (Thévenot, 2002) às cadeias de commodities agropecuárias no Brasil (Pompeia, 2021). Antes de analisarmos seu uso justificatório nas controvérsias ambientais, trataremos das fundamentações dessa ordem discursiva.

Em 2009, a agenda da SAN voltara a adquirir proeminência internacional. Nesse ano, a Cúpula Mundial sobre Segurança Alimentar, realizada em Roma, havia atribuído atenção especial ao combate à fome e à desnutrição. A cúpula fora precedida por trabalhos de um painel de especialistas de alto nível que se haviam reunido especificamente para tratar do futuro da alimentação humana. Operando com a pergunta-chave "Como alimentar o mundo em 2050?", o painel teve destaque pela associação que propôs entre estimativas da ONU sobre o crescimento da população até 2050 e o nível de aumento da produção agropecuária que seria necessário ocorrer para alimentá-la. Os especialistas indicaram, então, que para alimentar as 9,1 bilhões de pessoas que estimavam existir em 2050, seria necessário um aumento de $70 \%$ na produção de alimentos - sendo a linha de base o triênio 20052007 (FAO, 2009a). Entretanto, contrariando a retórica corporativa tradicional, o painel advertia que as políticas nacionais não deveriam somente privilegiar, de modo simplista, o aumento das respectivas produções agropecuárias nacionais, mas, principalmente, desenvolver e fortalecer as distintas dimensões que concorrem para promover o acesso a alimentos.

Nas negociações que resultaram na declaração da referida cúpula (FAO, 2009b), os números organizados pelo painel receberam amplo destaque, sendo basilares para a defesa de políticas de SAN nos mais diversos contextos nacionais. Também guardando coerência com o documento dos especialistas, ressaltava-se a importância de se atentar à dimensão do acesso, sem a qual não se poderiam considerar iniciativas consequentes de promoção da segurança alimentar.

Um semestre depois da cúpula, já em 2010, a FAO e a Organização para a Cooperação e Desenvolvimento Econômico (OCDE na sigla em português, e OECD, na sigla em inglês) sublinharam o potencial de aumento, no Brasil, da produção de commodities agropecuárias. Segundo as organizações internacionais, o país poderia aumentar sua produção em mais de $40 \%$ até 2019 , em comparação com o período de base 2007-2009. Ademais, assim como a cúpula havia salientado, a FAO e a OCDE argumentavam que a luta contra a fome seria primordialmente uma questão de acesso - sendo a pobreza um dos grandes entraves (OECD \& FAO, 2010).

Após ficarem relativamente estagnadas no triênio 1998-2000, as exportações relacionadas ao agronegócio no Brasil vinham crescendo de forma bastante acentuada: no decênio entre 2001 e 2011, elas haviam aumentado 298\% (cálculo dos autores com base em Mapa, 2016). Tratava-se de reflexo direto do boom das commodities, explorado ha- 
bilmente por estratégia público-privada (Delgado, 2012). Por sua vez, o boom era influenciado, em grande medida, pelo crescimento da demanda por esses produtos em países como a China. Do lado da oferta, havia um relativo esgotamento da capacidade de crescimento da produção em países tradicionalmente exportadores desses produtos, a exemplo dos Estados Unidos (BCB, 2012).

Não tardou para que os principais porta-vozes das associações empresariais começassem a derivar interpretações convenientes das projeções da FAO e da OCDE, assim como de estudos subsequentes de outros órgãos internacionais. Influenciadas pelo conjunto de fatores apresentados acima, as narrativas patronais sobre SAN seriam, portanto, gradualmente deslocadas para a ênfase nas vendas de commodities ao exterior.

Se tais argumentos sobre SAN passavam a ancorar-se acentuadamente nas exportações de commodities, seus usos justificatórios continuariam a ter suma relevância em controvérsias na esfera pública nacional. Dentre aquelas que, envolvendo as cadeias produtivas, agudizavam-se entre o final dos anos 2000 e começo da década seguinte, sobressaíam-se as relacionadas ao Código Florestal e às áreas protegidas (Pompeia, 2020b).

A instrumentalização, por interesses particulares, da ideia de SAN para promover iniciativas ambientalmente insustentáveis, alheias aos direitos das futuras gerações (Veiga, 2015), tampouco era nova (Belik, 2003). Mas teria, com as disputas relacionadas ao Código Florestal, um incremento considerável. No que se refere aos pleitos corporativos voltados à alteração do referido código, não se pode ignorar que alguns de seus aspectos precisavam de atualização para que se adequassem aos avanços técnico-produtivos produzidos no país.
No entanto, o problema é que as reivindicações das associações empresariais ultrapassaram em muito as atualizações necessárias, resultando, por fim, em graves mudanças da lei, cabendo enfatizar, dentre outras consequências, o enfraquecimento do dispositivo das áreas de preservação permanente (APPs) (Veiga, 2013).

Dentre os atores que mobilizaram narrativas alimentares para legitimar mudanças no Código Florestal, Roberto Rodrigues destacou-se. Em 2011, por exemplo, ele encorajou as mudanças na referida lei com base nas seguintes declarações:

Projeções da FAO apontam para a necessidade de aumento na produção de alimentos da ordem de $70 \%$ até 2050, cabendo ao Brasil uma parcela importante dessa oferta, em virtude de nossa área disponível, de água, de recursos humanos e de tecnologia. [...]. Para isso, uma legislação clara é fundamental. [...]. O novo Código Florestal é, portanto, uma necessidade [...]. (Rodrigues, 2011, p. B11).

Contrariando alertas das principais agremiações da ciência brasileira (ABC \& SBPC, 2012), que chamavam atenção para os potenciais altamente negativos das anistias a desmatadores recentes e do enfraquecimento de exigências para as APPs, a movimentação que resultou no enfraquecimento do Código Florestal foi avançada por concerto materializado sobretudo no Instituto Pensar Agropecuária (IPA) - entre associações lideradas pela agricultura patronal, indústrias e membros da FPA (Pompeia, 2020b).

Tal ação política significava um retrocesso em relação à participação importante que organizações do setor secundário haviam tido, em 2009, na $15^{\text {a }}$ Conferência das Partes da Convenção-Quadro das Nações Unidas sobre Mudança do Clima, quando 
defenderam a diminuição do desmatamento e a promoção de uma economia de baixo carbono (Pompeia, 2021). Também por essa razão, algumas indústrias de celulose, que haviam liderado as iniciativas climáticas em Copenhague, expressaram publicamente sua indignação com a atitude de outras representações relevantes do campo do agronegócio (Klabin, 2011). A fatura dessa miopia político-ambiental apareceria com ímpeto na década de 2020.

O segundo foco do bloco IPA/FPA, particularmente a partir de 2013, foi concentrado na oposição às demarcações de Terras Indígenas, ao reconhecimento de territórios tradicionais e à criação de Unidades de Conservação (Carneiro da Cunha et al., 2017; Carneiro da Cunha, 2021). As narrativas alimentares relacionadas à SAN difundidas por diversos agentes do campo do agronegócio seriam voltadas, então, para esses pleitos nitidamente patrimonialistas. De acordo com Roberto Rodrigues, “[...] uma das vantagens comparativas que a OCDE credita ao Brasil, quando sugere que nosso país aumente sua produção de alimentos em $40 \%$ até 2020, é a disponibilidade de terras agricultáveis". Entretanto, continuava o líder patronal,

[...] considerando os parques nacionais, estaduais e municipais, as Reservas Legais, as Áreas de Preservação Permanente, as terras para índios e quilombolas e outros, sobram aproximadamente 15 milhões de hectares para incorporar à fronteira agrícola, dos quais 10 milhões viriam da reconversão de pastagens e apenas 5 milhões seriam de cerrados ou florestas legalmente desmatadas. Com isso, fica bastante limitada nossa capacidade de atender a expectativa da OCDE (Rodrigues, 2014, p. 44).
Ao subsidiar tais argumentos - que continuavam a enfatizar a expansão horizontal das atividades agropecuárias, aprofundando o foco em vantagens comparativas, ao invés de investir com maior ímpeto no fomento a vantagens competitivas modernas (Veiga, 2013) -, o chefe da Embrapa Monitoramento por Satélite, Evaristo de Miranda, obteve proeminência (Miranda, 2009) ${ }^{4}$. Seus cálculos e interpretações têm sido usados com frequência por parte dos agentes dominantes do campo do agronegócio para tentar convencer a opinião pública de que há, no Brasil, um excesso de áreas protegidas, o que atrapalharia, por consequência, o crescimento da produção e exportação de commodities. Por sinal, Luiz Carlos Corrêa Carvalho, então presidente da Abag, mobilizaria os números de Miranda associados àqueles da FAO e da OCDE para argumentar que o país estaria "perdendo" terras (Carvalho, 2014, p. 46).

Narrativas amparadas nas contribuições que o Brasil poderia desempenhar para a segurança alimentar "global" ou "mundial" continuaram a ser mobilizadas em anos posteriores. Entre exemplos de formulações anunciadas em documentos de pleitos a presidentes e presidenciáveis, podem ser citadas aquelas do Global Agribusiness Forum - sobre o Brasil ser "garantidor da segurança alimentar no mundo" (2016, p. 1) - e as da Confederação da Agricultura e Pecuária do Brasil (CNA) e do Conselho das Entidades do Setor Agropecuário (Conselho do Agro) (2018, p. 10) - de que os brasileiros poderiam "[...] ser os campeões mundiais da segurança alimentar".

\footnotetext{
${ }^{4}$ Ver, a esse respeito, a esclarecedora contra-argumentação do Observatório do Clima (2019) a quantificações recentes de Miranda.
} 
Elas tampouco deixaram de ser utilizadas em contextos de contestações socioambientais. Recentemente, um de seus usos ocorre para fundamentar respostas às críticas internacionais direcionadas à política ambiental do governo Bolsonaro, sobretudo no que diz respeito ao aumento do desmatamento na Amazônia e às violações dos direitos de populações tradicionais. Em vídeo realizado por iniciativa do Mapa, com apoio da FPA, para anúncio em circuitos de investidores europeus, o narrador afirma que o Brasil tem o "[...] potencial de resolver dois grandes desafios mundiais: a segurança alimentar das pessoas e a conservação dos recursos naturais de nosso planeta" (Mapa, 2020a).

Além do mais, com o enfraquecimento de elementos fundantes da matriz de políticas de promoção da segurança alimentar - processo que se aprofunda com o desmonte institucional a partir, principalmente, de 2019 -, parcela dos atores do campo do agronegócio está voltando a investir na disputa pela agenda de SAN no país. "Mais do que a Frente da Agropecuária, nós somos a Frente do Abastecimento e da Segurança Alimentar", exclamou a então presidente da FPA, Tereza Cristina (Segurança..., 2018). Posteriormente, logo após ser convidada pelo presidente eleito a assumir o Mapa, um grupo do qual ela fez parte tentaria, sem êxito, mudar o nome da pasta para Ministério do Alimento e do Desenvolvimento Rural.

Ao unir as duas ordens discursivas - uma fundada no comércio exterior, outra no mercado interno -, as narrativas de SAN de parte dos agentes dominantes do campo visam, presentemente, à onipotência na esfera pública nacional e a seus possíveis desdobramentos em termos de legitimidade e influência política ${ }^{5}$. Durante a pandemia do novo coronavírus, as duas ordens têm sido empregadas para legitimar predisposições orçamentárias e tributárias favoráveis a atores prevalecentes nas principais cadeias de commodities. Conforme aponta a ministra da Agricultura, que procura equivaler a produção agropecuária à SAN, o “[...] Brasil é o celeiro do mundo. Alimentamos nossos 212 milhões de habitantes e exportamos para alimentar mais de 1 bilhão de pessoas no mundo" (Agronegócio..., 2020).

Contudo, enquanto tais agentes pretendem hegemonizar a agenda de SAN, a deterioração da transição nutricional em curso no país e suas influências na população intensificaram, principalmente nos últimos anos, uma ampla controvérsia alimentar relacionada aos determinantes comerciais da saúde - estratégias utilizadas pelo setor privado na promoção de produtos e escolhas que são nocivos à saúde (Kickbusch et al., 2016).

\section{Combate corporativo à regulação dos determinantes comerciais da saúde}

Até recentemente, a alusão a aspectos que conectam a alimentação à promoção da saúde pública era rara nas principais cartas programáticas do campo do agronegócio. Em 2018, esses documentos indicaram mudanças em relação a tal situação, ainda que de forma atenuada. A CNA e o Conselho do Agro (2018, p. 113) posicionaram a produção de "alimentos saudáveis" como um

${ }^{5}$ É importante salientar, nesse contexto, que as principais cartas programáticas de organizações intersetoriais do campo agronegócio situam a defesa do uso de agrotóxicos antes no âmbito de aumento e garantia da produtividade em si que, diretamente, na esfera das questões alimentares. 
dos grandes desafios para os 12 anos seguintes; por sua vez, a Coalizão Brasil Clima, Florestas e Agricultura (2018, p. 35) apresentou como meta o incentivo à "dieta saudável e de baixo carbono" - é possível observar, novamente, a relação entre temas ambientais e alimentares.

Ademais, a criação recente, no âmbito do bloco IPA/FPA, de uma comissão de "Alimentação e Saúde" (Pompeia: no prelo), e a revelação, em setembro de 2020, de uma nota técnica do Mapa que propunha ao Ministério da Saúde modificações no Guia Alimentar para a População Brasileira, também são manifestações de inflexão em curso, no campo do agronegócio, relativa ao tratamento das relações entre alimentação e saúde (Mapa, 2020b).

Antes de analisarmos as posições e justificações que têm sido mobilizadas por núcleos políticos do referido campo acerca desse tema, parece-nos indispensável explicitar o porquê de o assunto não ter obtido, até meados dos anos 2010, espaço relevante nos principais documentos dessas nucleações. Apesar de a noção de agronegócio ser contabilmente totalizante, incluindo tudo o que está relacionado, a montante e jusante, à agropecuária - e abrangendo, portanto, as indústrias de alimentos -, os núcleos intersetoriais que foram criados como sua tradução institucional, dando conformação progressiva à complexa arena política do agronegócio no Brasil, apresentaram notáveis déficits de representatividade (Pompeia, 2020a).

Por um lado, as entidades predominantemente industriais vinculadas às principais commodities agropecuárias (como soja, carnes e álcool-açúcar) têm apresentado, historicamente, participação considerável nos núcleos intersetoriais - como na Abag, no Fórum Nacional da Agricultura, no IPA e no Conselho do Agro ${ }^{6}$. Frequentemente detentoras de terras e amplamente focadas em produtos básicos e semimanufaturados, as corporações ligadas diretamente às commodities compartilham com segmentos liderados pela agricultura patronal um amplo conjunto de interesses, como crédito para investimento e custeio, temas fundiários, defesa agropecuária e tributação de commodities.

Por outro lado, a maior parcela das associações empresariais especializadas em alimentos e bebidas ultraprocessados - a exemplo daquelas representantes das indústrias de biscoitos, bolos e refrigerantes - têm apresentado inserção diminuta e inconstante nos núcleos (Pompeia, 2020a; 2020b). Alguns fóruns haviam promovido esforços para mudar essa situação, como o Conselho Superior do Agronegócio (Cosag/Fiesp). Criado entre 2006 e 2007, o Cosag procurou atrair a Abia e outras representações de atividades secundárias ligadas, por exemplo, a doces e panificação, quando de sua fundação (Fiesp, 2007). No entanto, depois de período inicial de entusiasmo com a engenharia institucional politicamente abrangente na Federação, as entidades de empresas de alimentos e bebidas ultraprocessados passariam a ter participação antes formal que factual nesse fórum (Pompeia, 2021).

De modo a examinar as dificuldades para tal aproximação política, devem ser consideradas tanto as disputas distributivas entre empresários da agricultura e das indústrias de maior elaboração nas distintas cadeias agroalimentares, quanto a maior autonomia que alguns segmentos a jusante dos complexos, como as fábricas de base trigo, detêm em relação à oferta nacional de determinadas commodities.

\footnotetext{
${ }^{6}$ Para análise sobre as diferenças institucionais e programáticas entre cada uma dessas organizações intersetoriais amplas, ver Pompeia (2021).
} 
Outro fator a explicar o déficit de atores das indústrias de produtos ultraprocessados no perímetro representacional de núcleos intersetoriais dominantes do campo do agronegócio são as diferenças programáticas. Com efeito, houve temas que se cristalizaram como reivindicações dessas nucleações - a exemplo de propostas sobre crédito, territórios indígenas, reforma agrária e agrotóxicos. Em contrapartida, assuntos como publicidade, rotulagem e teores de alimentos, mais diretamente caros às corporações de ultraprocessados, não conseguiram encontrar espaço adequado nas diferentes associações da arena intersetorial (Pompeia, 2021).

A distinção nos programas políticos evidencia-se inclusive na atuação bifocal de organizações que têm participado da maioria das nucleações predominantes do campo do agronegócio, como a União da Indústria de Cana-de-Açúcar (Unica). As usinas têm operado nos núcleos intersetoriais para organizar, sobretudo, o lobbying em relação à produção e à distribuição de seus produtos, mas, em contrapartida, relegam assuntos do consumo, como os relacionados ao excesso da ingestão de açúcar na população, para outros espaços ${ }^{7}$.

Pois bem, tal clivagem institucional e programática começaria a ser modificada na segunda metade dos anos 2010, quando os determinantes comerciais da saúde passavam a ser crescentemente criticados face à pandemia global de obesidade (Mialon et al., 2015). À época, a promoção do direito humano à alimentação adequada ampliara sua relevância na opinião pública internacional, e começava a adquirir maior influência no Brasil (Castro, 2015; Jaime et al., 2018).
Houve instrumentos substanciais para que seu avanço pudesse ocorrer no segundo quinquênio da década de 2010. Um deles foi a edição revisada da Política Nacional de Alimentação e Nutrição (PNAN), cujas diretrizes representaram um marco para o adensamento da defesa da agenda da alimentação adequada e saudável no país (MS, 2013). Dentre elas, constam a regulação relacionada aos alimentos, a organização da atenção nutricional, a vigilância alimentar e nutricional, a participação e o controle social, além da cooperação e articulação para a SAN. Outro instrumento basilar foi o relançamento do Guia Alimentar para a População Brasileira (MS, 2014), que reconfigurava as orientações alimentares.

Ambos os instrumentos estavam fundamentados em excepcionais avanços da ciência da nutrição, principalmente na classificação NOVA (Monteiro, 2009; Monteiro et al., 2011), que categoriza os alimentos segundo a extensão e o propósito de seu processamento: alimentos in natura ou minimamente processados; ingredientes culinários; alimentos processados; e alimentos ultraprocessados (Monteiro et al., 2016). De acordo com tal classificação, os ultraprocessados - como refrigerantes, embutidos, "salgadinhos de pacote" e guloseimas - caracterizam-se por serem prontos para o consumo, hiper-palatáveis e elaborados com ingredientes de baixo custo. Como resultado de sua formulação e composição, eles são nutricionalmente desbalanceados e tendem a ser consumidos em grandes quantidades (Monteiro et al., 2016). A propósito, entre os períodos de 2002-2003 e 2017-2018, os ultraprocessados aumentaram sua participação de $12,6 \%$ para $18,4 \%$

\footnotetext{
${ }^{7}$ Ver Unica - União da Indústria de Cana-de-Açúcar. Campanha Doce Equilíbrio (2017). Disponível em: <https://www.facebook.com/campanhadoceequilibrio/>. Acesso em: abr. 2020.
} 
em domicílios brasileiros - substituindo alimentos in natura ou minimamente processados, revelou a Avaliação Nutricional da Disponibilidade Domiciliar de Alimentos da POF (IGBE, 2020b).

Ao robustecer a identificação de relações causais entre, de um lado, o crescimento do consumo de alimentos e bebidas ultraprocessados, e, de outro, o aumento na ingestão calórica e no ganho de gordura corporal no país (ver, por exemplo, Louzada et al., 2015), a NOVA foi determinante para a ampliação do conhecimento científico de fatores contribuintes à deterioração característica da transição nutricional brasileira, como atestam os preocupantes números apresentados no início deste artigo.

Frente a críticas da agenda da alimentação adequada e saudável e a ações regulatórias e de educação alimentar - que ganhavam tração institucional para incidir sobre os determinantes comerciais da saúde -, não tardou a reação, defensiva, por parte de algumas representações das indústrias. Analisamos a seguir as principais justificações empresariais agenciadas nesse contexto, para então examinarmos a entrada do IPA na controvérsia.

Ainda em meados dos anos 2010, diferentes organizações industriais tinham se aproximado em seus discursos contrários ao Guia Alimentar. AAbia empenhou-se para convencer o Ministério da Saúde a não publicar o Guia com o corte dos alimentos por seu nível de processamento, pois, segundo ela, o instrumento de educação alimentar teria impacto negativo para as corporações. Além de defender que os interesses das firmas não poderiam ser afetados, a associação invocava posição "negacionista" ao afirmar que a classificação $N O V A$ não teria embasamento científico (Abia, 2015).
De forma similar, grandes indústrias de laticínios argumentaram que o enquadramento, no Guia, de parte dos derivados de leite como ultraprocessados seria prejudicial às empresas. Existiria, insistiam também, falta de fundamentação científica para a classificação. Ao lado da indicação de riscos comerciais às corporações e da contestação à classificação $N O V A$, os laticínios acrescentaram que haveria "causas diversas da obesidade e doenças crônicas não transmissíveis", as quais não seriam levadas em consideração nas críticas às indústrias (Mapa, 2015, p. 2).

Em seguida às reclamações sobre o Guia Alimentar, a Abia fez movimentações em defesa genérica dos "alimentos processados" (Abia, 2016, p. 47). Em agosto de 2015, a associação firmou um protocolo de intenções com o governo do estado de São Paulo que tinha como objetivo advogar pela “[...] importância dos alimentos processados para a sociedade brasileira" (Abia, 2016, p. 47). No ano seguinte, a associação lançaria, em articulação com o mesmo governo estadual, uma plataforma de comunicação para defender tais produtos na esfera pública (Abia, 2017).

A despeito das contestações corporativas, o Guia Alimentar fora lançado com base na classificação NOVA, e começara a produzir efeitos sobre as políticas do Ministério da Saúde, e também do MDS, mesmo que com dificuldades (Jaime et al., 2018). Além disso, o avanço de debates e negociações sobre o modelo de rotulagem de alimentos na Agência Nacional de Vigilância Sanitária (Anvisa, 2017) causava intensa preocupação em indústrias de alimentos e bebidas ultraprocessados (Abia, 2018; Pompeia: no prelo).

\footnotetext{
${ }^{8}$ Ver, a respeito, a excelente resposta de Louzada et al. (2019) a tais críticas.
} 
Foi nesse ambiente de agudização da controvérsia sobre alimentação e saúde pública que, na segunda metade de 2017, um amplo conjunto de entidades das diferentes indústrias de alimentos convergiram institucionalmente para criar a Rede Rotulagem (Abia, 2018). Na Rede, estavam tanto organizações com liderança de empresas de alimentos e bebidas ultraprocessados - como a Abia, a Associação Brasileira das Indústrias de Biscoitos, Massas Alimentícias e Pães \& Bolos Industrializados (Abimapi) e a Associação Brasileira das Indústrias de Refrigerantes e de Bebidas não Alcoólicas (Abir) - quanto aquelas ligadas mais diretamente às commodities agropecuárias - a exemplo da Unica, da Associação Brasileira das Indústrias de Óleos Vegetais (Abiove) e da Associação Brasileira de Proteína Animal (ABPA) (Abia, 2018).

Concomitantemente, algumas representações industriais impulsionaram, em meio a negociações no ambiente intersetorial do IPA, a conformação de um espaço específico para organizar contraposição político-narrativa à agenda da alimentação adequada e saudável. Uma comissão de "Alimentação e Saúde" seria, então, criada no órgão de lobbying posicionado na retaguarda da FPA. A aliança no IPA forneceria canais de atuação eficazes para o confronto, no Legislativo, a iniciativas para a regulação dos determinantes comerciais da saúde.

Por sinal, tem adquirido ímpeto, no Instituto, uma retórica - e ações dela desdobradas - que visa à apropriação da agenda da alimentação adequada e saudável (Pompeia: no prelo). Com o agenciamento da expressão "alimentação e saúde", um conjunto de engenharias institucionais foram construídas no Congresso Nacional com a finalidade de apresentar as indústrias de alimentos como as principais interessadas na promoção da nutrição adequada e da saúde pública no Brasil. São exemplos (1) a própria comissão mencionada acima, (2) uma agremiação multipartidária, a Frente Parlamentar de Alimentação e Saúde (FPAS), e (3) a subcomissão permanente de Alimentação e Saúde no âmbito da Comissão de Agricultura, Pecuária, Abastecimento e Desenvolvimento Rural (CAPADR), da Câmara dos Deputados (Pompeia: no prelo). No lançamento da FPAS, seu presidente, o deputado Evandro Roman (Partido Social Democrático, Paraná), declarou, não por acaso, o que seria a preocupação em "[...] desenvolver uma sociedade futura mais saudável” (Frente..., 2019).

Em segundo lugar, operam-se no IPA e em algumas representações industriais discursos que tencionam a diminuição relativa das responsabilidades corporativas sobre a obesidade. A operação ocorre por intermédio do agenciamento de argumentos que, evitando tratar diretamente das múltiplas influências de parte das indústrias de alimentos sobre o problema, sublinham sobretudo a diversidade de fatores que estariam relacionados à questão, com ênfase em dimensões individuais (Mialon et al.,2015). Salientando, desse modo, fatores como genética, condições endócrinas, stress e problemas de sono, um documento da FPA crítico a iniciativa legislativa para fomentar alimentação escolar mais adequada e saudável afirma que o "combate à obesidade deve levar em conta diversos fatores" (FPA, 2020, p. 1). Quando explicou o objetivo da Frente Parlamentar de Alimentação e Saúde, a Abia (2020, p. 25) mobilizou argumento semelhante. Para essa associação, o trabalho da FPAS “[...] está baseado em combater a obesidade e as doenças crônicas não transmissíveis por meio de uma abordagem ampla, considerando suas múltiplas causas". 
Uma parte dos agentes prevalecentes no campo do agronegócio têm operado, ainda, com uma terceira estratégia retórica, a de contestação direta da classificação NOVA e de outros fundamentos da agenda da alimentação adequada e saudável (Pompeia: no prelo). Assim como no procedimento descrito no parágrafo acima, trata-se de uma estratégia que vinha sendo utilizada com empenho pelas indústrias de alimentos, conforme apontado anteriormente neste artigo. Ela materializa-se exemplarmente em um raciocínio do deputado Roman no Congresso Nacional: remetendo à subcomissão de Alimentação e Saúde da CAPADR, o parlamentar afirmou que sua atuação seria necessária para "[...] destruir muitas inverdades ideológicas" sobre as questões alimentares (Roman, 2019).

\section{Considerações finais}

Ao passo que se impulsionam, no Brasil, estratégias empresariais de legitimação das principais cadeias de commodities agropecuárias - sendo as justificações alimentares um de seus eixos centrais -, é patente que tais estratégias contrastam com o aumento da prevalência, no país, tanto da obesidade quanto da insegurança alimentar grave. Havendo tal descompasso, revela-se importante atentar para os modos como atores políticos preponderantes nos sistemas agroalimentares se pronunciam e agem tanto em relação à questão da fome e da desnutrição quanto no que se refere àquela da obesidade e de outras doenças crônicas não transmissíveis relacionadas à alimentação.

Este artigo focou, consequentemente, as narrativas de agentes dominantes do campo do agronegócio no Brasil em relação a duas agendas alimentares: de um lado, a da segurança alimentar e nutricional (SAN); de outro, a da alimentação adequada e saudável. O objetivo foi examinar como as narrativas são agenciadas para finalidades políticas, e as maneiras pelas quais são modificadas em debates públicos.

Identificou-se que, quanto à agenda de SAN no Brasil, houve notável diversidade nas narrativas de atores prevalecentes das cadeias agroalimentares, sendo possível destacar as iniciativas capitaneadas pela Abag para exercer influência direta sobre ela. Contudo, um conjunto de fatores, a exemplo da consolidação de uma matriz de políticas públicas de combate à insegurança alimentar, retiraram paulatinamente a legitimidade dos discursos corporativos acerca do tema.

Passando por desestabilizações crescentes, o agenciamento predominante da noção de SAN por elites do campo foi deslocado na direção das contribuições do Brasil para as exportações de commodities. De fato, com base em interpretação seletiva de projeções de organizações internacionais, fortaleceram-se discursos sobre o país contribuir decisivamente para "alimentar o mundo". Como se analisou no texto, tais argumentos passaram a ser mobilizados com ímpeto em controvérsias públicas, como aquelas ligadas a temas socioambientais.

Em anos recentes, caracterizados pelo desmonte das políticas de segurança alimentar e nutricional no Brasil, parte dos atores da arena intersetorial do agronegócio têm operado com força para retomar incidência sobre a agenda de SAN no país. Porém, da mesma forma que a ampliação da insegurança alimentar grave evidencia obstáculos a esse intento, o aumento da prevalência de obesidade e das demais doenças crônicas não transmissíveis relacionadas à alimentação impõe novos desafios a representações dominantes no campo. 


\section{Referências}

ABC - Academia Brasileira de Ciências; SBPC - Sociedade Brasileira para o Progresso da Ciência. O Código Florestal e a Ciência: Contribuições para o Diálogo. Silva, J. A. A. (Org.); 2. ed. rev. São Paulo: SBPC, 2012.

Abag - Associação Brasileira do Agronegócio. Segurança alimentar: uma abordagem de Agribusiness. São Paulo: Abag, 1993.

Abag - Associação Brasileira do Agronegócio. $1{ }^{\circ}$ Congresso Brasileiro de Agribusiness - Relatório Técnico. São Paulo: Abag, 2002.

Abag - Associação Brasileira do Agronegócio. Plano de ação 2011-2014-2020 - propostas aos presidenciáveis. São Paulo: Abag, 2010.

Abia - Associação Brasileira da Indústria de Alimentos. Relatório Anual. São Paulo: Abia, 2015.

Abia - Associação Brasileira da Indústria de Alimentos. Relatório Anual. São Paulo: Abia, 2016.

Abia - Associação Brasileira da Indústria de Alimentos. Relatório Anual. São Paulo: Abia, 2017.

Abia - Associação Brasileira da Indústria de Alimentos. Relatório Anual. São Paulo: Abia, 2018.

Abia - Associação Brasileira da Indústria de Alimentos. Relatório Anual. São Paulo: Abia, 2020.

Agronegócio ajudou a segurar PIB durante a pandemia, diz ministra. Valor Econômico, Brasília, 15 ago. 2020. Disponível em: <https://valor.globo.com/agronegocios/ noticia/2020/08/15/agronegcio-ajudou-a-segurar-pib-durante-a-pandemia-dizministra.ghtml >. Acesso em: ago. 2020.

Alvarenga, O. M. 'É dando que se recebe'. O Globo. Rio de Janeiro, 24 ago. 1992. Economia, p. 17.

Anvisa. Relatório do Grupo de Trabalho sobre Rotulagem Nutricional. Brasília: Anvisa, 2017.

Asbran - Associação Brasileira de Nutrição. Posição em defesa e valorização do Guia Alimentar para a População Brasileira. 17 set. 2020. Disponível em: <https://www. asbran.org.br/noticias/posicao-em-defesa-e-valorizacao- -do-guia-alimentar-para-a-populacao-brasileira $>$. Acesso em: fev. 2021.

BCB - Banco Central do Brasil. Evolução Recente nos Preços de Commodities Agrícolas. Brasília: BCB, 2012.

Belik, W. Perspectivas para segurança alimentar e nutricional no Brasil. Saúde e Sociedade, 12, 12-20, 2003.

Belik, W. A Política Brasileira de Segurança Alimentar e Nutricional: Concepção e Resultados. Segurança Alimentar e Nutricional, 19, 94-110, 2012. doi: 10.20396/san. v19i2.8634614

Bittencourt de Araújo, N. A quebra de paradigmas. In: Abag. Caderno de 20 anos - Abag, 2013.

Boltanski, L.; Chiapello, E. The New Spirit of Capitalism. New York: Verso, 2005.

Bresser-Pereira, L. C. A construção politica do Brasil: sociedade, economia e Estado desde a Independência. São Paulo: Editora 34, 2015.

Cardoso de Mello, J. M.; Novais, F. Capitalismo tardio e sociabilidade moderna. In: História da vida privada no Brasil: contrastes da intimidade contemporânea [S.l: s.n.], p. 558-658, 1998.

Carneiro da Cunha, M. Paz entre agronegócio e direitos indígenas? Acabar com as ilegalidades é necessário, mas não suficiente. Revista Piauí, 172, Jan. 2021. Disponível em: <https://piaui.folha.uol.com.br/materia/ paz=-entre-agronegocio-e-direitos-indigenas/\#: :text$\mathrm{Na} \% 20$ interpreta $\% \mathrm{C} 3 \% \mathrm{~A} 7 \% \mathrm{C} 3 \% \mathrm{~A} 3 \mathrm{o} \% 20 \mathrm{da} \% 20 \mathrm{Cons}-$ titui $\%$ C3\%A 7\%C3\%A30\%20desejada,5\%20de $\% 20$ outubro $\% 20 \mathrm{de} \% 201988 . \&$ text $=\mathrm{A} \% 20$ interpreta $\%$ C3\%A7\%C3\%A3o\%20do\%20agroneg\%C3\%B3cio\%20 seria $\% 20$ juridicamente $\% 20$ inconceb $\%$ C3\%ADvel>. Acesso em: mar. 2021.

Carneiro da Cunha, M.; Caixeta, R.; Campbell, J. M.; Fausto, C; Kelly, J. A.; Lomnitz, C.; Londoño Sulkin, C. D.; Pompeia, C.; Vilaça, A. Indigenous peoples boxed in by Brazil's political crisis. Indigenous peoples boxed in by Brazil's political crisis. HAU: Journal of Ethnographic Theory, 7(2), 403-426, 2017. doi: 10.14318/hau7.2.033

Carvalho, L. C. C. Terras: usos e dificuldades no Brasil. Agroanalysis, 34(7), 2014. 
Castro, I. R. B. Desafios e perspectivas para a promoção da alimentação adequada e saudável no Brasil. Cadernos de Saúde Pública, 31(1), 7-9, 2015. doi: 10.1590/0102311XPE010115

Castro, I. R. B. A extinção do Conselho Nacional de Segurança Alimentar e Nutricional e a agenda de alimentação e nutrição. Cadernos de Saúde Pública, 35(2), 1-4, 2019. doi: 10.1590/0102-311x00009919

CNA - Confederação da Agricultura e Pecuária do Brasil; Conselho do Agro. O Futuro é Agro: 2018-2030. Brasília, DF: CNA, 2018.

Coalizão Brasil, Clima, Florestas e Agricultura. Visão 20302050. O Futuro das Florestas e da Agricultura no Brasil. São Paulo: Coalizão, 2018.

Delgado, G. C. Do capital financeiro na agricultura à economia do agronegócio: mudanças cíclicas em meio século (1965-2012). Porto Alegre: Editora da UFRGS, 2012.

Embrapa - Empresa Brasileira de Pesquisa Agropecuária. Visão 2030: o futuro da agricultura brasileira. Brasília, DF: Embrapa, 2018.

FAO - Food and Agriculture Organization; IFAD - International Fund for Agricultural Development; UNICEF United Nations International Children's Emergency Fund; WFP - World Food Programme; WHO - World Health Organization. The State of Food Security and Nutrition in the World 2020. Transforming food systems for affordable healthy diets. Rome: FAO, 2020.

FAO - Food and Agriculture Organization. The High-Level Expert Forum on How to Feed the World in 2050. Rome: FAO, 2009a.

FAO - Food and Agriculture Organization. Draft Declaration of the World Summit on Food Security. Rome, 16-18 November, 2009b.

FAO - Food and Agriculture Organization. Hunger and food insecurity. (2019), Disponível em: <http://www.fao. org/hunger/en/>. Acesso em: ago. 2020.

FAO - Food and Agriculture Organization. The Food Insecurity Experience Scale. 2020. Disponível em: <http:// www.fao.org/3/a-bl354e.pdf>. Acesso em: ago. 2020.
FIESP - Federação das Indústrias do Estado de São Paulo. Composição do Conselho Superior do Agronegócio. São Paulo: Fiesp, 2007.

FPA - Frente Parlamentar da Agropecuária. Resumo Executivo - PL no 4.501 de 2020. Brasília: FPA, 2020.

GAF - Global Agribusiness Forum. Manifesto de confiança ao governo brasileiro, 2016.

Global Panel on Agriculture and Food Systems for Nutrition. Future Food Systems: For people, our planet, and prosperity. Global Panel on Agriculture and Food Systems for Nutrition. London, 2020.

Governo estuda fazer leilão dos alimentos doados ao Fome Zero. Folha de S. Paulo, São Paulo, 19 fev. 2003.

Graziano da Silva, J. Segurança alimentar: uma agenda republicana. Estudos Avançados, 17(48), 45-51, 2003. doi: 10.1590/S0103-40142003000200004

IBGE - Instituto Brasileiro de Geografia e Estatística. Censo agropecuário 2006. Rio de Janeiro: IBGE, p.1-267, 2009. Disponível em: $<$ https://biblioteca.ibge.gov.br/visualizacao/ periodicos/51/agro_2006.pdf>. Acesso em: mar. 2021.

IBGE - Instituto Brasileiro de Geografia e Estatística. Pesquisa de Orçamentos Familiares 2017-2018: Segurança Alimentar. Rio de Janeiro: IBGE, 2020a.

IBGE. Pesquisa de Orçamentos Familiares 2017-2018: avaliação nutricional da disponibilidade domiciliar de alimentos no Brasil. 2020b.

IPCC - Intergovernmental Panel on Climate Change. IPCC Special Report on Climate Change, Desertification, Land Degradation, Sustainable Land Management, Food Security, and Greenhouse gas fluxes in Terrestrial Ecosystems. Approved Draft. 07 August 2019.

Jaime, P. Por que o Conselho Nacional de Segurança Alimentar e Nutricional é necessário? Jornal da USP, 07 jan. 2019.

Jaime, P.; Delmuè, D. C. C.; Campello, T.; Silva, D. O.; Santos, L. M. P. Um olhar sobre a agenda de alimentação e nutrição nos trinta anos do Sistema Único de Saúde. Ciência \& Saúde Coletiva, 23(6), 1829-1836, 2018. doi: 10.1590/1413-81232018236.05392018 
Kickbusch, I.; Allen, L.; Franz, C. The commercial determinants of health. Lancet Glob Health, 4(12), 895-896, 2016. doi: 10.1016/S2214-109X(16)30217-0

Klabin, R. Em vez de código florestal, Brasil terá código agrícola. [Entrevista concedia a André Palhano]. Folha de São Paulo, São Paulo, 29 de nov. de 2011. Disponível em: $<$ https://www1.folha.uol.com.br/fsp/mercado/11840-em-vezde-codigo-florestal-brasil-tera-codigo-agricola.shtml $>$. Acesso em: ago. 2020.

Klotz, E. Opinião. Prioridade da década: segurança alimentar. O Estado de S. Paulo. São Paulo. 05 jan. 1992, p. 52.

Louzada, M. L. C.; Baraldi, G. L.; Steele, E. M. et al. Consumption of ultra-processed foods and obesity in Brazilian adolescents and adults. Preventive Medicine, 81, 9-15, 2015. doi: 10.1016/j.ypmed.2015.07.018

Louzada, M. L. C.; Canella, D. S.; Jaime, P. C.; Monteiro, C. Alimentação e saúde: a fundamentação científica do guia alimentar para a população brasileira. 1. ed. São Paulo: Faculdade de Saúde Pública da USP, 2019. doi: 10.11606/9788588848344

Maluf, R., Menezes, F. Marques, S. B. Caderno segurança alimentar. Brasília: CONSEA, 2001.

Maluf, R.; Menezes, F.; Valente, F. Contribuição ao Tema da Segurança Alimentar no Brasil. Cadernos de Debate, IV, p. 66-88, 1996.

MAPA - Ministério da Agricultura e do Abastecimento. Mais do que uma política agrícola. Brasília: Mapa, 1998.

MAPA - Ministério da Agricultura, Pecuária e Abastecimento. Câmara Setorial da Cadeia Produtiva de Leite e Derivados. Reunião Extraordinária N. 10. Brasília: Mapa, 2015.

MAPA - Ministério da Agricultura, Pecuária e Abastecimento. Estatísticas do agronegócio. Brasília: Mapa, 2016.

MAPA - Ministério da Agricultura, Pecuária e Abastecimento. The Real Brazilian Agribusiness - How We Produce Your Food. 2020a. Disponível em: <https://www1.folha. uol.com.br/fsp/mercado/11840-em-vez-de-codigo-florestal-brasil-tera-codigo-agricola.shtml>. Acesso em: ago. 2020.

MAPA - Ministério da Agricultura, Pecuária e Abastecimento. Nota Técnica No 42/2020/DAEP/SPA/MAPA. Brasília:
Mapa, 2020b.

MAPA - Ministério da Agricultura, Pecuária e Abastecimento. AGROSTAT -Estatísticas de Comércio Exterior do Agronegócio Brasileiro. 2021. Disponível em: $<$ http:// indicadores.agricultura.gov.br/agrostat/index.htm $>$. Acesso em: mar. 2021.

Marques, P. E. M. Críticas e justificações em torno de alternativas agrícolas no estado de São Paulo. Tese de Livre-Docência. Esalq/USP, 2013.

Marques, P. E. M. Embates em torno da segurança e soberania alimentar: estudo de perspectivas concorrentes. Segurança Alimentar e Nutricional, v. 17, p. 78, 2015. doi: 10.20396/san.v17i2.8634795

Mialon, M.; Gomes, F. S. Public health and the ultra-processed food and drink products industry: corporate political activity of major transnationals in Latin America and the Caribbean. Public Health Nutrition, 22(10), p. 1898-1908, 2019. doi: $10.1017 / \mathrm{S} 1368980019000417$

Mialon, M.; Sêrodio, P.; Scagliusi, F. B. Criticism of the NOVA classification: who are the protagonists? World Nutrition, 9(3), p. 176-240, 2018. doi: 10.26596/wn.201893176240

Mialon, M.; Swinburn, B.; Sacks, G. A proposed approach to systematically identify and monitor the corporate political activity of the food industry with respect to public health using publicly available information. Obesity Reviews, 16, 519-530, 2015. doi: 10.1111/obr.12289

Miranda, E. E. Alcance territorial da legislação ambiental e indigenista - Quanta terra está legalmente disponível para a agricultura?. Brasília: Embrapa, 2009.

Monteiro, C. A. A dimensão da pobreza, da desnutrição e da fome no Brasil. Estudps Avançados, 17(48), 7-20, 2003. doi: 10.1590/S0103-40142003000200002

Monteiro, C. A. Nutrition and health. The issue is not food, nor nutrients, so much as processing. Public Health Nutrition, 12(5), 729-31, 2009. doi: 10.1017/ S1368980009005291

Monteiro, C. A.; Levy, R.; Claro, R. M.; De Castro, I. R. R.; Cannon, G. Increasing consumption of ultra-processed foods and likely impact on human health: evidence from Brazil. 
Public Health Nutrition, 14(1), 5-13, 2011. doi: 10.1017/ S1368980010003241

Monteiro, C. A.; Cannon, G. Levy, R. B.; Moubarac; J. C.; Jaime, P. C.; Martins, A. N. B.; Canella, D.; Louzada, M.; Parra, D. NOVA. A estrela brilha. [Classificação dos alimentos. Saúde Pública.]. World Nutrition, 7(1-3), 28-40, 2016.

Montero, P. Controvérsias religiosas e esfera pública: repensando as religiões como discurso. Religião $e$ Sociedade, 32(1), 15-30, 2012. doi: 10.1590/S010085872012000100008

Montero, P.; Arruti, J. M.; Pompa, C. Para uma antropologia do político. In: Lavalle, A. G. (Org.). O horizonte da politi$c a$ : questões emergentes e agenda de pesquisa. São Paulo: Unesp, 2012, p. 145-184.

MRE - Ministério das Relações Exteriores. Discursos selecionados do Presidente Luiz Inácio Lula da Silva. Brasília: Fundação Alexandre de Gusmão, 2008. Disponível em: $<$ http://funag.gov.br/loja/download/505-discursos_selecionados_lula.pdf $>$. Acesso em: mar. 2021.

MS - Ministério da Saúde. Secretaria de Atenção à Saúde. Política Nacional de Alimentação e Nutrição. Brasília: MS, 2013. Disponível em: <http://bvsms.saude.gov.br/bvs/ publicacoes/politica_nacional_alimentacao_nutricao.pdf $>$. Acesso em: mar. 2021.

MS - Ministério da Saúde. Guia Alimentar para a População Brasileira. Brasília: MS, 2014. Disponível em: $<$ https:// bvsms.saude.gov.br/bvs/publicacoes/guia_alimentar_populacao_brasileira_2ed.pdf $>$. Acesso em: mar. 2021.

MS - Ministério da Saúde. Vigitel Brasil 2018. Brasília: MS, 2019. Disponível em: $<$ https://portalarquivos2.saude. gov.br/images/pdf/2019/julho/25/vigitel-brasil-2018.pdf>. Acesso em: mar. 2021.

Neves, M. F. Vai agronegócio! 25 anos cumprindo missão vitoriosa. Sertãozinho: Editora Canaoeste, 2016.

Observatório do Clima. Fatos Florestais: caem mitos que opõem produção à conservação no Brasil. 2019. Disponível em: $<$ https://www.youtube.com/watch? $=$ rM4SktDid2Q $>$. Acesso em: jun. 2019.

OECD - Organisation for Economic Co-operation and Development; FAO - Food and Agriculture Organiza- tion. Agricultural Outlook 2010-2019. Rome: OECD, FAO, 2010.

Paiva, J. B.; Magalhães, L. M.; Santos, S. M. C. et al. A confluência entre o "adequado" e o "saudável": análise da instituição da noção de alimentação adequada e saudável nas políticas públicas do Brasil. Cadernos de Saúde Pública, 35, 1-12, 2019. doi:10.1590/0102-311x00250318

Peliano, A. M. Depoimento. In: Rodrigues, R. (Org.). Ney Bittencourt: o dínamo do agribusiness. São Paulo: SRB, 1996, p. 28-29.

Pompeia, C. 'Agro é Tudo': simulações no aparato de legitimação do agronegócio, Horizontes Antropológicos, 26(56), 195-224, 2020a. doi: 10.1590/s0104-71832020000100009

Pompeia, C. Concertação e Poder: o agronegócio como fenômeno político no Brasil, Revista Brasileira de Ciências Sociais, 35(104), 1-17, 2020b. doi: 10.1590/3510410/2020

Pompeia, C. Formação Política do Agronegócio. São Paulo: Editora Elefante, 2021.

Pompeia, C. Inflexões representativas, comunicacionais e institucionais em associações nacionais das indústrias de alimentos. Cadernos de Saúde Publica, No Prelo.

Poore, J.; Nemecek, T. Reducing food's environmental impacts through producers and consumers. Science, 360(6392), 987-992, 2018. doi: 10.1126/science.aaq0216

Popkin, B.; Reardon, T. Obesity and the food system transformation in Latin America. Obesity Reviews 19, 1028-1064, 2018. doi: 10.1111/obr.12694

Public Health England. Excess Weight and COVID-19: Insights from new evidence. 2020. Disponível em: $<$ https://assets.publishing.service.gov.uk/government/ uploads/system/uploads/attachment_data/file/907966/ PHE_insight_Excess_weight_and_COVID-19_FINAL. pdf $>$. Acesso em: ago. 2020.

Recine, E.; Fagundes, A.; Silva, B. L. et al. Reflections on the extinction of the National Council for Food and Nutrition Security and the confrontation of Covid-19 in Brazil. Revista de Nutrição, 33, e200176, 2020. doi: 10.1590/1678$9865202033 \mathrm{e} 200176$

Rodrigues, R. Depoimento. Fome Zero ajuda setor agrícola, 
diz ministro. O Estado de S. Paulo. 03 jan. 2003. Economia, p. B5.

Rodrigues, R. Opinião. Competitividade e segurança alimentar. Folha de S. Paulo. São Paulo, 12 jan. 1993. Agrofolha, p. 2.

Rodrigues, R. Opinião. Consenso ou bom senso? Folha de S. Paulo. São Paulo, 09 abr. 2011. Economia, p. B11.

Rodrigues, R. Opinião. Terras para índios. Agroanalysis, 34(1), 44, 2014.

Frente parlamentar vai debater ações de combate à obesidade. Agência Câmara Notícias, Brasília, 30 de maio de 2019. <https://www.camara.leg.br/noticias/558779-frenteparlamentar-vai-debater-acoes-de-combate-a-obesidade/ $>$. Acesso em: abr. 2020.

Roman, E. Comissão de Agricultura, Pecuária, Abastecimento e Desenv. Rural. 2019. Disponível em: $<$ https:// www.camara.leg.br/evento-legislativo/55197>. Acesso em: mar. 2021.

Segurança alimentar e força da agricultura marcam discursos da posse de Tereza Cristina. AgênciaFPA, Notícias, 22 fev. 2018. Disponível em: $<$ https://agencia.fpagropecuaria. org.br/2018/02/21/segurancaalimentar-e-forca-da-agricultura-marcam-discursos-da-possede-tereza-cristina/>. Acesso em: jun. 2019.

Sen, A. Poverty and Famines - an essay on entitlement and deprivation. Oxford: Clarendon Press, 1981.

SNA - Sociedade Nacional de Agricultura. Anais do $5^{\circ}$ Congresso de Agribusiness. Segurança Alimentar e Cadeia Produtiva. Rio de Janeiro, 24-25 nov. 2003.
Souza, H. Depoimento. In: Rodrigues, R. (Org.). Ney Bittencourt: o dínamo do agribusiness. São Paulo, SRB, 1996.

Thévenot, L. Which road to follow? The moral complexity of an 'equipped' humanity. In: Law, J.; Mol, A. (Eds.). Complexities: Social Studies of Knowledge Practices, Durham and London, Duke University Press, p. 53-87, 2002.

Tilman D.; Clark, M. Global diets link environmental sustainability and human health. Nature, 515, 518-522, 2014. doi: 10.1038/nature13959

UN - United Nations. International Conference on Nutrition. World Declaration and Plan of Action for Nutrition, 1992.

Veiga, J. E. Os estertores do Código Florestal. Campinas, SP: Armazém do Ipê, 2013.

Veiga, J. E. Para entender o desenvolvimento sustentável. São Paulo: Editora 34, 2015.

Willett, W.; Rockström, J.; Loken, B.; Springmann, M.; Lang, T.; Vermeulen, S.; Murray, C.J.L. Food in the Anthropocene: the EAT-Lancet Commission on healthy diets from sustainable food systems. The Lancet, 393(10170), 447-492, 2019. doi: 10.1016/S0140-6736(18)31788-4

WB - World Bank. An Overview of Links between Obesity and Food Systems; Implications for the Food and Agriculture Global Practice Agenda. Washington, The World Bank Group, 2017.

WHO - World Health Organization. Noncommunicable Diseases (NCD). Country Profiles. Geneva: World Health Organization, 2018. 